\title{
Phylogeny of Helianthus and related genera
}

Oléagineux, Corps Gras, Lipides. Volume 8, Numéro 1, 22-5, Janvier - Février 2001, La filière

\author{
Auteur(s) : Edward E. SCHILLING, Department of \\ Botany, University of Tennessee, Knoxville TN \\ 37996-1100, USA.
}

Summary : Molecular phylogenetic studies have contributed significantly to our understanding of the phylogenetic relationships of Helianthus, although several problems remain to be resolved. Molecular data have resolved problems with the circumscription of Helianthus. Its sister group is Phoebanthus, a narrowly distributed genus of two species from the state of Florida. The sister group to the HelianthusPhoebanthus clade is a diverse set of taxa that occurs in Mexico and South America. These include species now classified as part of the paraphyletic Viguiera as well as such distinctive genera as Tithonia, Simsia, Pappobolus, Scalesia, Lagascea, and Alvordia. Incongruence between results based on chloroplast and nuclear-based data sets suggests that hybridization has been involved in the evolutionary history of this group. The nearest outgroup to the clade containing Helianthus is composed of members of Viguiera sect. Maculatae, which are trees and shrubs of Mexico. Other basally diverging groups in the subtribe Helianthinae to which Helianthus belongs are primarily woody members now classified in Viguiera from Mexico and nearby areas. Within Helianthus, divergence appears to be recent, based on an overall lack of divergence between species. The chloroplast-based tree suggests that Helianthus includes four phylogenetic lineages, whereas the nuclear ITS sequence data suggests that the perennial species are paraphyletic relative to the rest of the genus, with basally diverging branches consisting of species confined to the southeastern US. Because there is a lack of divergence among many groups of species, more variable markers will be required to resolve fully relationships within Helianthus.

Keywords : Helianthus, sunflower, Asteraceae, chloroplast DNA, ITS, molecular phylogenetics, tournesol, ADN de chloroplaste, moléculaire phylogenetics.

\section{ARTICLE}

The purpose of this paper is to broaden the perspective on sunflower (Helianthus annuus) by taking a look at its wild relatives. To do so requires moving away from the agricultural fields that are the standard place for research on sunflowers and instead consider habitats in North America, Mexico, and South America that are the locations where wild relatives of sunflowers occur.

There are several major points that emerge from our research on sunflower relatives. The first is that we can settle arguments about exactly what does and does not belong in Helianthus, the genus of the cultivated sunflower. It can be clearly shown that Helianthus is a distinct group that under natural conditions occurred only in North America. A second point is that the Helianthus genus has no really close relatives. The only exception is a genus called Phoebanthus, but there is a possibility that this really is just a part of Helianthus. A third point is that patterns of distributions of phylogenetic markers that we have analyzed suggests that wide hybridization is not uncommon within the larger group to which the sunflowers belong. 
A fourth point is that when we look within Helianthus, we find that all of the species are very similar to each other at the molecular level. We infer from this that divergence to form the current set of species in the genus is surprisingly recent.

Sunflowers are members of the plant family Asteraceae, and in this family what looks superficially like a single flower is really an aggregation of many, individually small flowers [1]. The family is the largest family of flowering plants, with over 25,000 species, and experts divide it into about 15 or so subunits called tribes. The Heliantheae is one of the largest of these tribes, and it has well over 2,000 species. It is defined by a number of features, including having heads with both central disk and outer ray flowers (these often yellow in color), an imbricate involucre and paleate receptacle, and carbonized cypselas with a pappus of awns or scales. The view of this tribe has changed since molecular phylogenetic data started being used in the 1980s. The traditional view of it as the basal, most primitive part of Asteraceae has been greatly changed. Some of the data in this paper will highlight just how recently derived this group is.

The Heliantheae tribe is further subdivided into units called subtribes. The composition and limits of these are still being argued about, but the subtribe in which the true sunflowers are placed is pretty clear. The characters that define this subtribe, Helianthinae, are highly technical [2]. These include having sterile ray flowers, a single stigmatic surface on the style, striations in the cypsela walls, and anthochlor floral pigments. The subtribe forms a logical unit to consider for analyzing sunflower relationships. Classification of subtribe Helianthinae into genera has proven to be difficult with just morphological features. This is where molecular characters are proving to be useful. Molecular data provide a large number of characters that have the advantage of being selectively neutral.

The tree that we obtained for the phylogeny of subtribe Helianthinae based on analyses of the changes in the chloroplast genome $[3,4]$ is shown in Figure 1 . The sampling procedure that we used here was restriction site analysis, which looks for changes throughout the chloroplast genome. The data are summarized by an analytical procedure called maximum parsimony analysis that produces a graph or tree in which the branching pattern provides an estimate of ancestral/descendant relationships. This tree is based on data from almost half of the 400 species of the subtribe, and is pretty well supported statistically.

We also looked at a gene region encoded in the nuclear DNA, the ITS or internal transcribed spacer region [5]. This is part of the region of the genome that encodes the sequences for the RNAs that will form the ribosomes. The ITS is subdivided by the stretch that codes for the $5.8 \mathrm{~S}$ subunit, and the two spacers on either side of this have a total of a little over 500 base pairs of sequence. The tree obtained for the ITS region (Figure 1) is very similar, at least at its lower branches, to the tree obtained from the chloroplast genome. There are, however, some differences between the trees from the different gene regions in the most derived parts of the tree. Note that ITS is biparentally inherited in contrast to the maternally inherited chloroplast genome.

A couple of general points emerge from the overall phylogeny (Figure 1). The first is that Viguiera as currently circumscribed is what we call a paraphyletic group. Its members are found in more than one of the lineages shown in the tree. In fact, they occur from the top to the bottom of it. Thus, biologically speaking Viguiera is not a particularly useful name. Until a new generic-level classification is proposed, how-ever, it will be necessary to continue to use Viguiera as a scientific name for species that are not necessarily closely related to one another. 
A second point is that a pattern of chromosome number evolution is seen. The outgroups and the basal groups of the subtribe have a chromosome number of $x=18$. There is some variation in basal lineages for chromosome numbers, most notably the presence of $x=8$ as the base for Viguiera section Heliomeris. But there is a shift to the number of $x=17$ that is found throughout most of the subtribe (including Helianthus), and this shift helps to define this as a monophyletic lineage.

The molecular phylogenetic data show that Helianthus is a well-defined group that is clearly placed just within the $x=17$ lineage. This result is strongly supported by multiple changes in the chloroplast DNA data [6]. It is also confirmed in the ITS data set [7]. This makes it possible to clearly define Helianthus. In the past, the key feature used to define Helianthus was the caducous pappus, which has two awns, with intermediate scales often lacking. By contrast, the most widespread pappus form among its relatives is to have a pappus with both awns and scales, and to have them remain firmly attached even after the cypsela is released. However, the caducous type of pappus is found not only in Helianthus but also in some other plants, notably Pappobolus. There are a couple of other technical features that must be used in combination with the pappus to define Helianthus. These include the fact that the bracts associated with each flower, or pales, have an apex that is trilobed, rather than simply acute as in its relatives. Helianthus also has a cluster of cells at the tip of each style branch that form prominent (at the microscope level) appendage.

Molecular phylogenetic data also allow us to show what is not a Helianthus. The South American species that have been placed in the past in Helianthus are all part of a different lineage, and the name Pappobolus is the correct one for them. There are some 38 species of Pappobolus, and these occur in the Andes Mountains of Colombia, Ecuador, and Peru [8]. Pappobolus is part of the derived group of the subtribe (Figures 1 and 2).

There are also two species from Mexico that have been considered to belong to Helianthus [9, 10]. This again was because they have the same type of caducous pappus as in Helianthus. Molecular data show that the two species are unrelated to each other or to Helianthus. Viguiera similis is part of the group that occurs in Baja California, Mexico, and has a chromosome base number of $x=18$. Viguiera phenax (also called Helianthus ludens) is part of the derived group of the subtribe, and it occurs in dry barren areas in the states of Chihuahua and Durango in north central Mexico.

Next we can consider what are the close relatives to Helianthus. The nearest Helianthus relative is a small genus called Phoebanthus. The molecular data place it close or even within Helianthus (Figure 1). Phoebanthus is a genus of only two species, both of which are restricted to the state of Florida in the southeastern USA. There is one diploid and one tetraploid species. A defining feature of the genus is its curious, underground tubers, and it occurs in open pine woodlands that are subject to periodic fires.

Outside of Phoebanthus, the next group that shares a common ancestor is a very large assembly of about 300 species that includes several genera (Figure 1). According to the molecular phylogeny, each of these is about equally distant from Helianthus. We use the term sister groups to describe two lineages that share a common ancestor. Thus, Helianthus has a very large and complex sister group, which we will consider here only briefly.

The first data set that we obtained was from the chloroplast DNA analysis, and for this region of the tree it initially gave a nice, well-resolved picture [3]. One curiosity was that Tithonia and Simsia, which are both quite distinct and easily recognized genera, were placed close together, with very strong data 
support. Simsia has strongly flattened cypselas [11]. Tithonia is well defined by its fistulose peduncle that is it flares out and is hollow internally [12]. The two genera had never been considered to be related closely with each other. Another puzzle came when we looked at the two South American species of Simsia, which is otherwise found in Mexico and Central America. One of them, Simsia dombeyana, had the identical chloroplast DNA pattern as the South American Viguiera, and differed strikingly from the other Simsias. Yet not only is it a perfectly typical Simsia, it actually is barely different in appearance from one of the most distinct species of Simsia, Simsia foetida [11].

Consideration of the nuclear ITS data provides an explanation of this situation [5]. The ITS tree (Figure 2) agrees with morphology in placing Simsia dombeyana within Simsia, and as sister to its close morphological congener, Simsia foetida. Thus it looks like the chloroplast tree reflects a reticulation event. This was likely to have been produced by a past hybridization event that resulted in the transfer of the chloroplast otherwise typical of the South American Viguiera to Simsia dombeyana. A similar pattern is found for Tithonia. Analysis of more samples showed that Tithonia is actually diphyletic in the chloroplast tree - its species are placed in two distinct parts of the tree (Figure 2). In contrast, the ITS data show that Tithonia is monophyletic and is close to a group called Viguiera subgenus Amphilepis, which it resembles morphologically.

These examples suggest that wide hybridization has occurred in the past within the subtribe. They thus suggest that wide hybridization may be a possible line to explore to obtain germplasm resources to modify the common sunflower.

We can also consider what groups are outside of Helianthus and its large sister group. These turn out to be groups that are predominately from Mexico. Many of these groups are characteristically woody. For example, Viguiera puruana is a tree sunflower of Viguiera section Maculatae that reaches heights of up to 15 meters and grows in an area of Michoacan, Mexico that is within the wintering grounds of the famous Monarch Butterflies. The phylogeny provides insights into the biogeographic history of the subtribe. From a Mexican ancestry, there appear to have been several movements into South America. The only incursion of the subtribe into eastern North America is Helianthus. Furthermore the low amount of divergence in molecular characters between non-Mexican and Mexican groups suggests that these movements were relatively recent. This fits with a pattern that is emerging for several groups of Asteraceae. In particular, it suggests that they were a floral component of the great biotic interchange that took place after the Central American land bridge closed about three million years ago.

We can now consider aspects of molecular divergence within Helianthus. There are four major points to be made here. One is that there may also be reticulation involved with Helianthus and Phoebanthus. A second is that the basal groups of the Helianthus lineage are from the southeastern USA. Third is that the annual species including the cultivated $H$. annuus form a derived, monophyletic group. Finally, lack of differences for molecular features suggests that divergence in the genus is quite recent.

\section{CONCLUSION}

A summary of the overall phylogeny of Helianthus is shown in Figure 3. Chloroplast DNA characters [6], shown on the left of the figure, suggest that there are four major, equally divergent lineages, and further that Phoebanthus is actually an ingroup to one of these formed by the perennial species of Helianthus. 
The ITS tree [7] differs somewhat in suggesting that Phoebanthus is outside of Helianthus as its sister group, and that the perennials are actually a paraphyletic group with two species, $H$. heterophyllus and H. carnosus, placed in a basal position in the genus.

A look at geographic distributions shows that the basal clades of the genus are found in the extreme southeastern USA. The two species of Phoebanthus are both endemic to Florida, as are two of the basal species of Helianthus. Helianthus heterophyllus is found along the Atlantic and Gulf coasts, and Helianthus porteri occurs in granite outcrops centered in Georgia. In combination with geological history, this suggests a possible explanation that the lineage leading to Helianthus after arriving in North America from Mexico has been pushed back to southeastern North America during one or more recent glaciations, and that much of the current suite of species is very recently derived.

The lack of molecular divergence in Helianthus is striking, and it has been a nuisance in trying to come up with molecular-level characters to answer questions about relationships in the genus. Table provides a summary of the levels of divergence for the markers that we have been using in our laboratory. Divergence is less than $0.25 \%$ for the chloroplast DNA and only up to about $4-5 \%$ for the more rapidly evolving ITS region. We went to a chloroplast region that has been shown to be very rapidly evolving in many plants, the trnT-trnL-trnF region. This region includes a couple of spacers and an intron. These are stretches of DNA that can be expected to have a rapid rate of change because they are not under the functional constraints that coding regions would be. We did a pilot study of three species that represent a wide spectrum of divergence in Helianthus, $\mathrm{H}$. angustifolius, $\mathrm{H}$. giganteus, and $\mathrm{H}$. porteri. For the first spacer, we found four insertion/deletion differences (indels) and a single base pair change. For the trn $\mathrm{L}$ intron the three species were identical for 467 bases of sequence. For the second spacer, we found two more indels and another base pair difference. Thus, for a total of some 1,400 base pairs we obtained a grand total of 6 indels and 2 base pair changes. To put this in perspective, different individuals of a single species of Primula were reported recently to have 22 base pair differences and 5 indels for this same region. This illustrates that Helianthus has relatively little variation at the molecular level, from which we infer that it is very recently diverged.

We will close this paper with a brief survey of some of the highlights of diversity in the genus Helianthus. Despite its apparent recent diversification, there are still some notable differences among species of the genus. The phylogenetic tree based on ITS sequences will be used as a guide.

The most basally diverging lineages of Helianthus are formed by two perennial species, $H$. heterophyllus and $H$. carnosus. These are both species of the coastal plain of the southeastern USA. Both of these species have a basal rosette of leaves and produce a scape-like flowering stalk with just one or a few heads. This habit is quite unlike that seen in the cultivated sunflower.

The next most basally diverging branches of the tree are formed by two annual species, both with restricted distributions in the southeastern USA. These are both unusual for Helianthus in being selfcompatible. Helianthus agrestis is found in the state of Florida, and it is a robust plant that is often found in relatively wet habitats along rivers or streams. It is different enough in technical features, notably the odd protuberances on its cypselas, that it has been questioned whether or not it should really be included in Helianthus [9]. 
Helianthus porteri, in contrast, occurs in the seasonally very dry habitats of the granite outcrops that occur in the piedmont region of Alabama, Georgia, and South Carolina. This species has been considered by most taxonomists to be a member of Viguiera (or of Heliomeris, when this is recognized as being distinct from Viguiera), and the name Viguiera porteri is used for it in most of the extensive ecological literature about the species. But both chromosome counts and breeding studies anticipated the molecular phylogenetic results in showing that it is correctly placed in Helianthus [13].

The remaining perennial species of Helianthus form a group that is not resolved by molecular data. These are distinguished from one another primarily by vegetative features. Included among these are more rosette-forming species of the southeastern USA, such as the rayless $\mathrm{H}$. radula and another rock outcrop species (this one on sandstone), H. longifolius. Many perennial species are more widespread, and include series of species that grade into one another across their ranges and thus might better be considered geographical races or varieties than distinct species. Some of these species, such as $H$. maximiliani and $H$. grosseserratus, are now expanding their ranges, apparently utilizing roads as corridors of dispersal.

The perennial species include a number of polyploid species. Notable among these is the Jerusalem artichoke, Helianthus tuberosus, which is a cultivated plant of relatively minor importance [14]. One of the goals of our studies has been to try to unravel the genomic relationships of the polyploids, but there is too little variation in the molecular markers we have used so far to make progress in this.

Finally, the annual species group of which the domesticated sunflower ( $H$. annuus) is a part forms a monophyletic clade, and this is the group that has been of most direct interest to sunflower breeders. There is even some resolution within this clade, which matches a pattern that has been frequently encountered that annual species tend to exhibit higher levels of molecular-level variation than related perennials. The annual species can be separated into three major groups based on the ITS data set: one group includes $H$. petiolaris and related species; a second group with $H$. debilis and its relatives, and a third group with $H$. annuus. Loren Rieseberg and his colleagues at Indiana University have made some elegant studies [15-18] in which they show that several hybrid species have originated from the combination of $H$. petiolaris and $H$. annuus. This provides another set of examples where reticulation through hybridization has been important in the phylogeny of this group.

\section{Acknowledgements}

I thank the organizers of the International Sunflower Conference in Toulouse for the opportunity to present this research, particularly B. Schweisguth, L. Lot and A. Bervillé. A large number of people have contributed to the research summarized here, including J. Panero, O. Spring, F. Batista, N. Lopes, L. Rieseberg, R. Linder, R. Noyes, R. Jansen, H. Buschmann, U. Eliasson, M. Johnson, P. Heise, P. Cox and M.L. Schmid. Funding for various projects has been provided by the American Philosophical Society, the U.S. National Science Foundation and the Hesler Fund of the University of Tennessee.

\section{REFERENCES}

1. BREMER K (1994). Asteraceae: Cladistics and Classification. Portland, Oregon: Timber Press.

2. ROBINSON H (1981). A revision of the tribal and subtribal limits of the Heliantheae (Asteraceae). Smithsonian Contributions to Botany, 51: 1-102. 
3. SCHILLING EE, JANSEN RK (1989). Restriction fragment analysis of chloroplast DNA and the systematics of Viguiera and related genera (Asteraceae: Heliantheae). Am J Botany, 76: 1769-78.

4. SCHILLING EE, PANERO JL (1996). Relationships in Heliantheae subtribe Helianthinae based on chloroplast DNA restriction site analysis. In: HIND DJ, BEENTJE HJ, eds. Compositae: Systematics. Proceedings of the International Compositae Conference, vol. 1: 361-76.

5. SCHILLING EE, PANERO JL (1996). Phylogenetic reticulation in subtribe Helianthinae. Am J Botany, 83: 939-48.

6. SCHILLING EE (1997). Phylogenetic analysis of Helianthus (Asteraceae) based on chloroplast DNA restriction site data. Theor Appl Genet, 94: 925-33.

7. SCHILLING EE, LANDER CR, NOYES RD, RIESEBERG LH (1998). Phylogenetic relationships in Helianthus (Asteraceae) based on nuclear ribosomal DNA internal transcribed spacer region sequence data. Systematic Botany, 23: 177-87.

8. PANERO JL (1992). Systematics of Pappobolus (Asteraceae: Heliantheae). Systematic Botany Monographs, 36: 1-195.

9. HEISER CB Jr, SMITH DM, CLEVENGER S, MARTIN WC (1969). The North American sunflowers (Helianthus). Memoirs of the Torrey Botanical Club, 22: 1-218.

10. ROGERS CE, THOMPSON TE, SEILER GJ (1982). Sunflower species of the United States. Fargo, South Dakota: National Sunflower Association.

11. SPOONER DM (1990). Systematics of Simsia (Compositae: Heliantheae). Systematic Botany Monographs, 30: 1-90.

12. LA DUKE JC (1982). Revision of Tithonia. Rhodora, 84: 453-522.

13. SCHILLING EE, HEISER CB (1981). Infrageneric classification of Helianthus (Compositae). Taxon, 30: 393-403.

14. HEISER CB Jr (1976). The Sunflower. Norman, Oklahoma: University of Oklahoma Press.

15. RIESEBERG LH (1991). Homoploid reticulate evolution in Helianthus: evidence from ribosomal genes. Am J Botany, 78: 1218-37.

16. RIESEBERG LH (2000). Crossing relationships among ancient and experimental sunflower hybrid lineages. Evolution, 54: 859-65.

17. RIESEBERG LH, VAN FOSSEN C, DESROCHERS A (1995). Hybrid speciation accompanied by genomic reorganization in wild sunflowers. Nature, 375: 313-6.

18. RIESEBERG LH, SINERVO B, LINDER CR, UNGERER M, ARIAS DM (1996). Role of gene interactions in hybrid speciation: evidence from ancient and experimental hybrids. Science, 272: 741-5. 
Illustrations

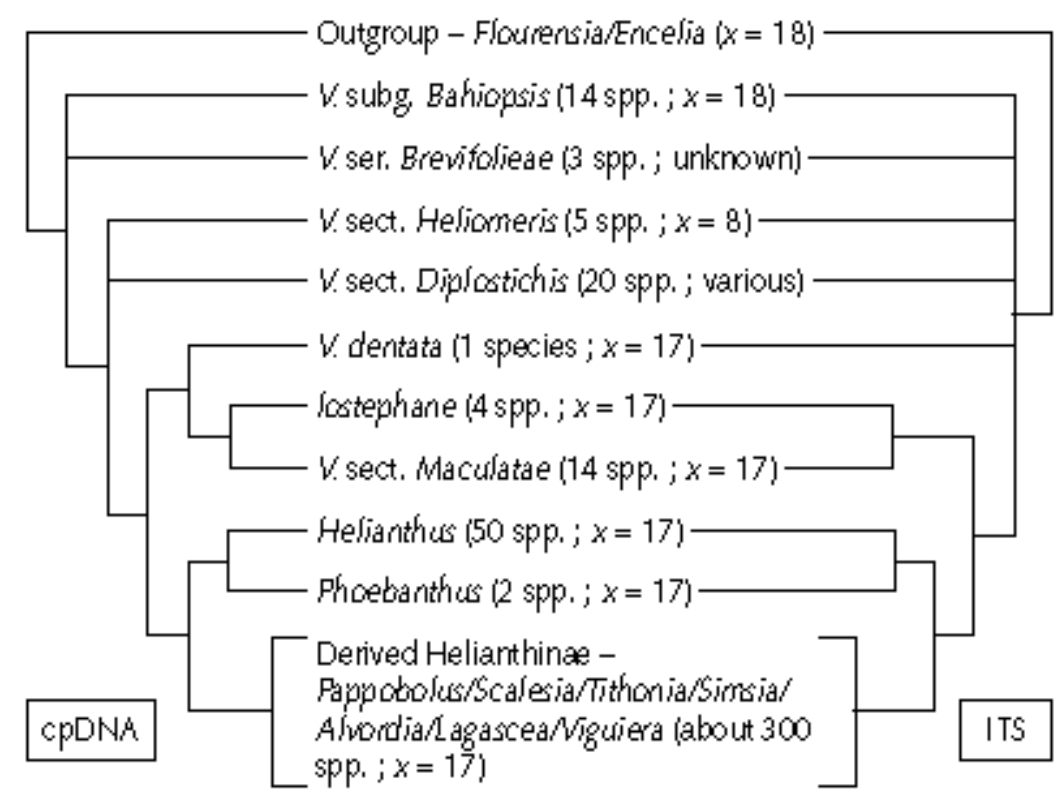

Figure 1. Phylogenetic relationships within subtribe Helianthinae based on chloroplast DNA restriction site characters (left) and DNA sequences of the ITS region (right). Number of species and base chromosome numbers of each group shown in parentheses (summarized from Schilling and Jansen [3], Schilling and Panero [4, 5]). V. = Viguiera . 


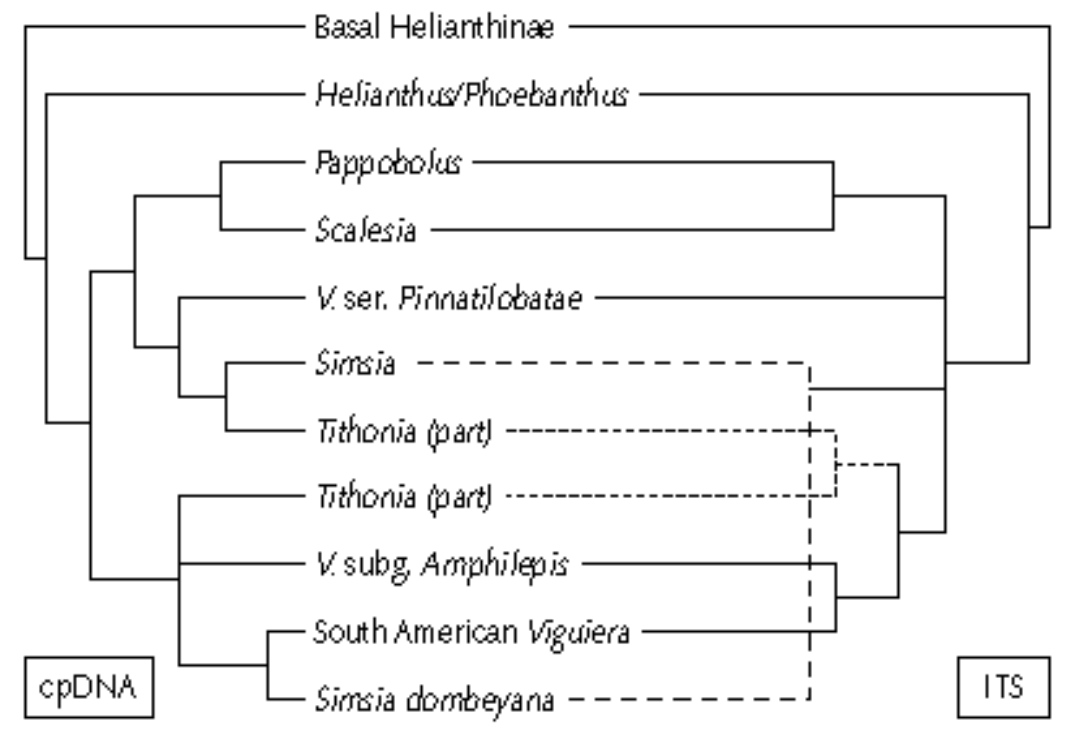

Figure 2. Phylogenetic reticulation inferred from incongruent placement of samples of subtribe Helianthinae in trees based on chloroplast DNA restriction site data (left) and ITS sequences (right). Broken lines show differing placements of Simsia dombeyana and Tithonia in the ITS tree compared to the cpDNA tree (summarized from Schilling and Panero [4, 5]).

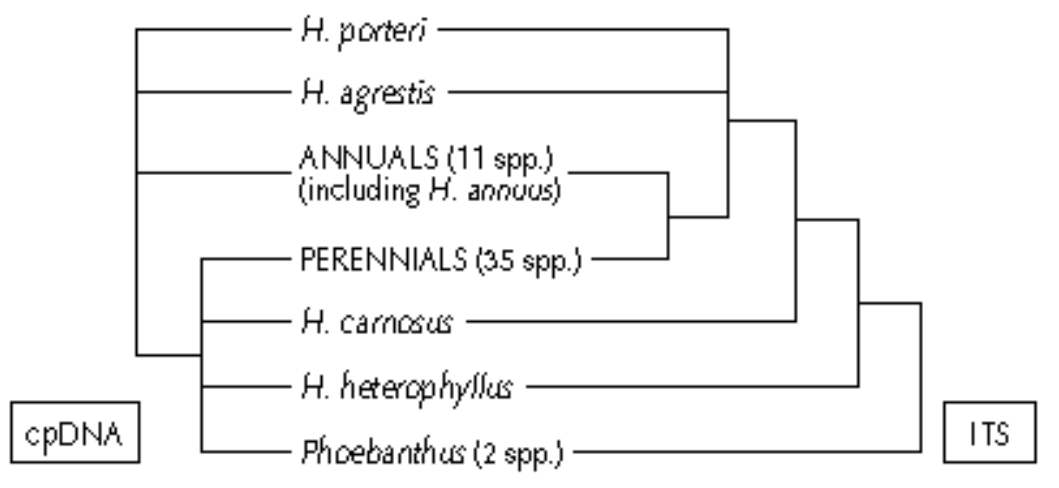

Figure 3. Molecular phylogeny of Helianthus and Phoebanthus based on chloroplast DNA restriction site data (left) and ITS sequences (right) (summarized from Schilling [6] and Schilling et al. [7]). 
Table. Examples of molecular divergence in Helianthus for chloroplast DNA restriction sites ( $c p D N A)$, nuclea ribosomal internal transcribed spacer (ITS) and chloroplast encoded $\mathrm{tm} T$-tmL-tmF spacer/intron regions. bp: base pars; indels: insertion/deletion changes.

\begin{tabular}{|c|c|c|c|}
\hline & & cpDNA & ITS \\
\hline Within Helianthus & & $0.0 .25 \%$ & $0.4 \%$ \\
\hline Helianthus-Phoe banthus & & $0.0 .12 \%$ & $2.4-5.5 \%$ \\
\hline \multicolumn{4}{|c|}{ “ cpDNA spacer/intron sequenœe data for Helianthus angustifolius, H. giganteus, H. parteri } \\
\hline & length bp & indels & bp changes \\
\hline tnT-tonL spaœr & 562 & 4 & 1 \\
\hline tonL intron & 467 & 0 & 0 \\
\hline$t n \mathrm{n}-\mathrm{t} n \mathrm{nF}$ spaœr & 88 & 2 & 1 \\
\hline Total & 1,417 & 6 & 2 \\
\hline
\end{tabular}

